\section{Epidemiology of HIV, HBV and HCV and the Safety of Blood Products \\ Concerning Stark K, et al: Infections with HIV, HBV and HCV among blood donors in Germany 1998 and 1999. Infus Ther Transfus Med 2002;29:305-307}

In table 1 of their recent contribution Stark and co-workers list the number of donations from infected first-time and repeat donors reported to the Robert Koch-Institut, divided according to the different viruses (HIV, HBV, and HCV), to whole-blood and plasmapheresis donations and to the two time periods second half of 1998 and 1999. From these data, it should be possible to draw conclusions with respect to prevalence (first-time donors) and incidence (repeat donors) of the three infections among whole-blood and plasmapheresis donors. However, in the accompanying text these conclusions were either missing altogether or were incomplete.

1) Among first-time donors, each donation counted in the table corresponds to one donor. The rate of marker-positive donations may be interpreted as prevalence of infection in donor applicants/candidates for the respective donations (whole blood versus plasmapheresis) Among whole-blood donors this prevalence remains approximately constant for all three viruses from the second half of 1998 to the year 1999. Among plasmapheresis donors, however, there is a dramatic increase from 2/6,921 to $39 / 9,900$ reported infections. Either 10 times as many infected persons chose to present for plasmapheresis donation in 1999 than in the second half of 1998 or not all infected first-time donors were reported to the Robert KochInstitut in 1998. In favor of the latter possibility is the fact that the Advisory Group 'Blood' (Arbeitskreis Blut), in its recommendation (votum 24), expressly requires reporting of confirmation of suspected infection after repeatedly reactive results in screening tests also for first-time donations.

2) According to table 1, in 1999 plasmapheresis donors have a significantly higher prevalence of HCV than whole-blood donors, but this is neither mentioned nor discussed in the text.

3) There is a contradiction between the table's information on HBV prevalence in 1998 and 1999 in whole-blood donors and the comment in the text. According to table 1, there is a slight increase from 146.9/100,000 donations in the second half of 1998 to $150.1 / 100,000$ donations in 1999 . The text, however, reports a significant decrease between 1998 and 1999 with a $p$ value of 0.04 .
4) In addition, Stark et al. listed the rate of infectious donations of repeat whole-blood and plasmapheresis donors. Conclusions on the incidence of the infections in the respective donor pools can only be drawn if it is known from how many donors these donations are derived. A mathematical model exists which allows calculation of the residual risk from the incidence of the infection in the donor population and the interval between donations. Stark and co-workers did not do the calculations ' ... because the data on the time intervals between repeat donations were incomplete or inconsistent in a high proportion of the reporting services.' Even if the poor quality of their data did not allow the calculation, Stark and co-workers could (and should perhaps) have mentioned that plasmapheresis donors generally donate much more frequently than (10 times as frequently?) whole-blood donors. The lower rate of HCV-infectious donations from repeat plasmapheresis donors consequently corresponds to a higher incidence of $\mathrm{HCV}$ infections in that donor population.

5) The last sentence states that 'the data on infections among blood donors demonstrate the high safety of blood products in Germany and the benefit of careful donor selection.' Unfortunately, the first point is not adequately discussed to clearly substantiate this indisputable observation. First-time donors who test positive do not pose a risk with respect to the infections for which they are tested. More problematic are the significant differences in prevalence between collectives if one assumes that an increased prevalence of known parenterally transmitted infections at some point in the future may be related to an increased prevalence of a still unknown parenterally transmitted infection. HIV was an example of this in the past. Prevalence of a virus infection in a donor group only allows to draw limited conclusions with respect to the much more important incidence in that donor group. Nevertheless, it is remarkable that not only the prevalence, but very likely also the incidence of $\mathrm{HBV}$ and $\mathrm{HCV}$ infections, is higher in plasmapheresis than in whole-blood donors. This may be irrelevant for the safety of plasma derivatives due to NAT testing and virus inactivation procedures. Quarantine should maintain the safety of noninactivated plasma for therapeutic purposes at least with respect to HCV. Problems could possibly arise if plasmapheresis donors are also requested to donate cellular blood products. It would be of utmost interest to analyze prevalence and incidence of the relevant virus infections in thrombapheresis donors separately as the characteristics of thrombapheresis donation 
(frequent donation possible, comparatively higher recompensation) closely resemble that of plasmapheresis. The case of HCV transmission by a platelet concentrate with extremely low HCV RNA concentration (approximately 2 viruses $/ \mathrm{ml}$ ) documents that the risk stemming from fresh $\mathrm{HCV}$ infections has not been reduced to zero in spite of NAT testing [1]. This is all the more true for $\mathrm{HBV}$ for which NAT is not yet mandatory.

The second point, the benefit of careful donor selection, has not been touched at all in the publication of Stark et al. The authors could have cited, to present just one example, the 4 times higher prevalence of $\mathrm{HBV}$ and HCV in the normal population than in blood donors which was established in a study of the Robert Koch-Institut [2].

In conclusion, only careful analysis of the existing data and a thorough discussion will allow us to draw conclusions which might permit further improvement of the already extraordinary high safety standard in transfusion medicine.

W.H. Gerlich, Gießen; G. Caspari, Brandenburg

\section{References}

1 Schüttler CG, Caspari G, Jursch CA, Willems WR, Gerlich WH, Schaefer S: Hepatitis $\mathrm{C}$ virus transmission by a blood transfusion negative in nucleic acid amplification tests for viral RNA. Lancet 2000;355:41-42.

2 Thierfelder W, Hellenbrand W, Meisel H, Schreier E, Dortschy R: Prevalence of markers for hepatitis A, B and C in the German population. Results of the German National Health Interview and Examination Survey 1998. Eur J Epidemiol 2001;17:429-435.

\section{Authors' Reply}

The objective of our paper was, in accordance with the editor and the reviewers, to concisely present the epidemiologic data on HIV, HBV, and HCV infection among blood donors in Germany for the second half of 1998 and for 1999. We abstained from an extensive and too speculative discussion because our own data were limited to this relatively short time period of 1.5 years. The analysis of data of the following years will allow a broader discussion (manuscripts in preparation). On the basis of the low prevalence and incidence of HIV, $\mathrm{HBV}$ and HCV infections among blood donors we concluded that blood safety continued to be high in Germany.

In the following we respond to the points raised by Gerlich and Caspari:

1) Among first-time plasma donors HCV seroprevalence was substantially higher in 1999 compared to the second half of 1998. However, this increase did not reflect a long-term trend. In fact, the prevalence rate was 326/100,000 in 1997 [1], 104/100,000 in 1998 (whole year), and 222/100,000 in 1999. Unpublished data showed that the prevalence in 2001 was similar to that in 1998. It is not valid to draw far reaching conclusions based only on the data from 1998 and
1999. Due to space limitations we did not present the data by Glück et al. [2] in the table of our publication. However, the respective papers were referenced and are easily accessible.

2) A higher HCV seroprevalence among first-time plasma donors compared to blood donors was observed in 1997, 1999 and 2000, but not in 1998 and 2001. Again the data do not allow to draw any definitive conclusion regarding systematic differences between plasma donors and blood donors.

3) It is true that the HBV prevalences in 1998 (second half) and 1999 are not significantly different. The $p$ value of 0.04 given in the paper is not correct for this comparison but refers to the decrease in HBV prevalence when comparing the whole year of 1998 (HBV prevalence 171/100,000) with $1999(150 / 100,000)$.

4) There are several models for the calculation of the residual risk of infections by blood donations [e.g. 2]. Such calculations are only valid if they are based on relatively precise estimates of the interdonation intervals. Data on interdonation intervals in Germany is only given as time frames (0-6 months, 6-12 months, 12-24 months, $>24$ months) as defined by the advisory committee blood (Recommendation 22, November 16, 1999). Since data on the actual frequency was not available and therefore any assumption on the higher incidence of HCV among plasmapheresis donors population was speculative, a risk calculation would not be scientifically sound. Studies are underway to arrive at a more precise estimate of interdonation intervals for Germany. These data will allow to calculate residual risks.

5) From 1997 to 2001 there is no consistent and significant difference in the prevalence of HIV, HBV and HCV infections between whole-blood and plasma donors. It appears not useful to speculate about any difference in incidence without valid data (e.g. on the true interdonation intervals).

It has been reported in several studies from different countries that blood donors are a selected population with significantly lower HIV, HBV and HCV seroprevalences than in the general population. A detailed comparison of prevalence studies among blood donors and the general population may deserve a review paper but was beyond the scope of our paper. We suppose that most readers of this journal are familiar with the HBV and HCV prevalence data in the general population in Germany.

\section{K. Stark, R. Offergeld, Berlin}

\section{References}

1 Glück D: Risiko der HIV-, HCV- und HBV-Übertragung durch Blutpräparate. Aktuelle Daten 1997 und 1998. Infusionsther Transfusionsmed 1999;26:335-338.

2 Schreiber GB, Busch MP, Kleinman SH, Korelitz JJ: The risk of transfusiontransmitted viral infections. N Engl J Med 1996;334:1685-1690. 